\title{
Chasing shared understanding in drilling operations
}

\author{
Torgeir K. Haavik
}

Received: 15 March 2010/Accepted: 7 October 2010/Published online: 22 October 2010

(C) The Author(s) 2010. This article is published with open access at Springerlink.com

\begin{abstract}
Lack of shared understanding is frequently found to be the main cause when accidents are investigated. Still, few studies explicitly explore and document the causal effects of shared understanding in successful work. Thus, the attribution of insufficient shared understanding as an accident cause lacks the substantiation of shared understanding as a contributor to successful work. In this article a case of measurement discrepancies in an offshore drilling operation is studied, and in the elaboration of the case shared understanding is found not to qualify as a condition with significant impact on the collaborative work. One important reason for this is the epistemological inadequacy of the different concepts of shared understanding. Although more critical research on shared understanding is needed before one can conclude more generic on this topic, the findings are important to the current development of Integrated Operations where shared understanding is pointed out as an important target area.
\end{abstract}

Keywords Shared understanding - Coordination . Cooperative work - Distributed cognition - Integrated operations

A scene from an offshore drilling operation: at two different stages of the operation, the measurements of the same depth show different results. Due to

T. K. Haavik ( $\square)$

Department of Sociology and Political Science/NTNU Social Research Ltd, Norwegian University of Science and Technology, NTNU Social Research, 7491 Trondheim, Norway

e-mail: torgeir.haavik@samfunn.ntnu.no

\begin{abstract}
different types of risks and success criteria, the significance of the depth measurement reliability is different in the short and the long time perspective. The relevant time perspective also differs for the actors involved; while the drilling engineers have a short time perspective and are willing to accept an accuracy in the range of decimetres, the reservoir engineers have a longer time perspective and require less uncertainty of measurements. What role does shared understanding between the actors play in such a situation?
\end{abstract}

\section{Introduction and objective}

Modern industries are characterised by a high degree of division of labour. The cooperation between different disciplines and expertises within organisations, and the coordination of the contributions of the different actors into collective achievements to ensure safe and efficient operations in risk-exposed industries is thus an important field for research. The topic has been treated in a range of work place studies within many different domains such as aviation (Endsley 1999; Hutchins 1995a, b; Suchman 1996; Weick and Roberts 1993), health care (Munkvold and Ellingsen 2007; Tjora 2000), underground control centres (Heath and Luff 1992), the petroleum industry (Almklov 2006; Hepsø 2006; Rolland et al. 2006), and in more general workplace studies (Engeström and Middleton 1996; Heath et al. 2000).

The recurrence of the theme shared understanding, in different forms, indicates its relevance for collaborative work. However, the nature of shared understanding as such is not clear. There exists a range of different conceptualisations of the phenomenon (see Sect. 2), and the role of 
these concepts in collaborative work is generally taken for granted and not scrutinised.

Lack of shared understanding is often pointed out as a main cause of failure (see e.g., Klein 2005; MacMillan et al. 2004; Roth et al. 2006). Accidents are often shown to coincide with, and thus believed to be caused by, a breakdown in shared understanding. Conversely, a high degree of shared understanding is seen as a contributor to safe and efficient operations. The US Army thus states that

"(...) shared situational awareness, coupled with the ability to conduct continuous operations, will allow Force XXI armies to observe, decide, and act faster, more correctly, and more precisely than their enemies" (TRADOC 1995, paragraph 1-2),

and in connection with integrated operations, it is stated that "shared understanding has a significant impact on the ability of teams to coordinate their work and perform well" (Grøtan et al. 2009:2221). This straightforward coupling between shared understanding and safe and efficient collaborative work is problematic, since shared understanding is an underspecified phenomenon, and shared situation awareness, for example, is "elusive and ill-defined, and does not lend itself easily to traditional scientific evaluation" (Nofi 2000:71). Actually, an alignment of understanding and awareness is not always desirable:

"Agents within a system each hold their own situation awareness, which may be very different from (although compatible with) that of other agents. (...) We should not always hope for, or indeed want, sharing of this awareness, as different system agents have different purposes" (Stanton et al. 2006:1288).

The writings on group think (Janis 1972), conceptual slack (Schulman 1993), requisite variety (Weick 2007) and ambiguity (Antonsen 2009) is also a reminder that shared understanding is not necessarily an precondition for safe and efficient collaborative work.

The objective of this article is to explore different conceptualisations of shared understanding by applying them to a real case of collaborative work where the actors' goals and success criteria are not unanimous. The relations between the concepts will be investigated, as well as their ability to explain and affect the safety and efficiency of collaborative work process. The results are believed to be important to the further development of integrated operations, an operating regime whose safe and efficient collaboration is often held to go be connected to shared understanding (see e.g., Grøtan et al. 2009; Kaarstad et al. 2009).

Different concepts of shared understanding-common ground, shared situation awareness and common information spaces (CIS) — are compared and applied to a case to explore their contribution to the cooperative work. The field of study is an onshore rig team within an international petroleum company. Being responsible for the offshore drilling operations, the rig team writes the drilling program and follows up its execution. In practice, this work involves cooperation between the rig team and a range of other actors such as the offshore rig crew and the drilling contractor, onshore geology and reservoir experts and service companies with different types of specialist expertise that are needed in the different stages of a well project.

\section{Shared understanding in the literature}

A characteristic feature of modern industries is the division of labour that renders possible a high degree of specialisation and the accomplishment of highly complex work. A challenging implication of this division of labour is the work related to coordinating the different contributions- to put together what has been divided. It is possible to identify two different approaches to describe and explain this type of work. One describes the cognitive processes involved in the work, and underscores that these processes are distributed over humans and artefacts rather than being individual mental processes. Just as the cognitive processes of a sociotechnical system can be described as distributed (Artman and Garbis 1998; Hutchins 1995a, b), the way the system may have a common situational understanding is best described as a distributed understanding ${ }^{1}$ (in contrast to overlapping). This approach will be revisited towards the end of the article, when the conclusions are drawn.

The other tradition, which is thoroughly explored in this article, focuses on shared understanding as a central entity for successful collaborative work. The terminology, however, is not uniform across the disciplines following this tradition; each discipline adopts its own concept and fills it with its own meaning. With slightly different connotations, the concepts are many; common understanding, team shared awareness, shared understanding, group situational awareness, shared cognition, team awareness, coherent tactical picture, common ground, shared work space awareness, team cognition, shared mental models and common information spaces (see e.g., Bannon and Bødker 1997; Nofi 2000; Roth et al. 2006).

In the following, three distinct concepts for shared understanding will be shortly reviewed: common ground, shared situation awareness and CIS. The selection is made with the purpose of covering different disciplines and different epistemological perspectives; a social constructive

\footnotetext{
$\overline{1}$ Stanton et al. (2006) calls it distributed situation awareness. Here distributed understanding is used to avoid unnecessary confusion with Endsley's (2000) concept.
} 
view, a realistic view and a sociotechnical, relativistic view. The selection thus covers some central aspects of knowledge and collaboration; the involved actors perceive, and they share their perceptions through social and technical interaction. Thereafter, an occurrence from the observation study will be reviewed and serve as a case for exploring how the different types of shared understanding relate to the coordination and accomplishment of the work.

It is important to note that it is not the qualities and pertinence of the different concepts as such that are investigated, but the way the concepts are used to explain the outcome of collaborative work.

\subsection{Common ground}

The notion of common ground is rooted in Herbert Clark's contribution theory. It was coined to describe the way people achieve joint understanding, in the form of "mutual knowledge, mutual beliefs, and mutual assumptions" (Clark and Brennan 1991:127) in the course of conversation. The process by which common ground is achieved between two or more participants is called a grounding process. The grounding criterion is met when "the contributor and his or her partners mutually believe that the partners have understood what the contributor meant to a criterion sufficient for current purposes" (Clark and Brennan 1991:129).

The contribution theory that serves as the theoretical base for the formation of common ground is primarily a theory of discourse. That is, the focus is on the process of and the resources available for sharing already achieved understandings rather than the process of gaining new knowledge about the world. The significance of media through which the communication between the participants takes place is evaluated only for media which are dedicated to communication support. This has been subject to the criticism that contribution theory and common ground does not take into account other aspects of communication and cooperation such as embodied phenomena and the material and social environment (Koschmann and LeBaron 2003).

Common ground as a basis for cooperation involves a social constructivist approach to cooperative work. Basing cooperation on common ground, or shared understanding, implies much focus on communication about the world and little focus on accounting for what makes up this world (see e.g., Beers et al. 2005). It also builds on the assumption that the participants are informing each other, rather than creating new knowledge together; hence the social constructivist label to distinguish it from the more sociotechnical epistemology of common information spaces (see Sect. 2.3).

Clark and Brennan adapt Grice's (1975) principles of least effort in the grounding process into an adjusted principle of least cooperative effort; "In conversation, the participants try to minimise their collaborative effort-the work that both do from the initiation of each contribution to its mutual acceptance" (Clark and Brennan 1991:135). This is obviously relevant for the cost-efficient achievement of common ground. How this common ground in turn affects the production of safe and efficient collaboration, however, is not well documented.

\subsection{Shared situation awareness}

The notion of shared situation awareness has been widely used in the field of human factors. Central contributions have come from the field of psychology, and aviation has been one of the industries where it has found application. It builds on the more generic concept of situation awareness, defined as "the perception of elements in the environment within a volume of time and space, the comprehension of their meaning, and the projection of their status in the near future" (Endsley 1988:97). As an extension of this concept, shared situation awareness refers to the intersection of situation awareness among several actors. Endsley and Jones define shared situation awareness as "the degree to which team members possess the same $\mathrm{SA}^{2}$ on shared SA requirements" (Endsley and Jones 1997:37).

Situation awareness is based on a realistic epistemology, with a focus on objective perception of cues, comprehension of their meanings and projection to forecast future events presupposes a view where phenomena are out there, ready to be perceived, and that the challenge is to perceive them as precisely as possible.

Although widely used and accepted, the use of deficient situation awareness as a condition explaining why accidents happen (e.g. Aeronautica Civil de Colombia 1996; National Transportation Safety Board 1994), has been criticised by Billings (1996) and Dekker and Hollnagel (2004) for being deficient and tautological, and that the usage takes place.

"without further specification of the psychological mechanism that might possibly be responsible for the observed behaviour-much less of how such mechanism could force the sequence of events toward its eventual outcome" (Dekker and Hollnagel 2004:79).

\subsection{Common information spaces}

In the field of computer-supported cooperative work, a concept that has received much attention is (CIS). Although the concept is vaguely defined and has been used in many different ways, a definition that was coined in the

\footnotetext{
${ }^{2}$ Situation awareness.
} 
early $1990 \mathrm{~s}$ is still referred to by many contemporary writers (e.g. Bossen 2002; Fields 2005; Munkvold and Ellingsen 2007; Rolland et al. 2006). A CIS comprises "the artifacts that are accessible to a cooperative ensemble as well as the meaning attributed to these artifacts by the actors" (Schmidt and Bannon 1992:21). A CIS is a space in which people can work cooperatively by

"maintaining a central archive of organizational information with some level of 'shared' agreement as to the meaning of this information (locally constructed), despite the marked differences concerning the origins and context of these information items. The space is constituted and maintained by different actors employing different conceptualizations and multiple decision making strategies, supported by technology" (Schmidt and Bannon 1992:16).

These spaces can apply in situations where people are co-present in time and space, or they can apply to settings where people work "across time and space boundaries" (Bannon and Bødker 1997:2). In the latter case, the issue of stability is important since the CIS is to support distributed work in the course of time. People who work across large distances, perhaps not even aware of each other's presence and work contributions, need to relate to the same information and its attributed meanings. To support settings that differ with respect to boundaries of space and time, Bannon and Bødker (1997) suggest that the nature of the CIS need to be dialectic. Within local communities of practice (Brown 1991), the CIS might be open and malleable, allowing for interpretation and negotiation. CIS that serve cooperative work distributed over time and space, on the other hand, must allow for closure and immutability to function as immutable mobiles (Latour 1987) that can be transported between locations.

The concept of CIS is hence more relativistic than those of common ground and shared situation awareness. Whereas situation awareness is referred to as ecological realism (Endsley 2000; Flach 1995), CIS resemble the sociotechnical relativistic epistemology as described by Latour (e.g. 1999). The focus is on alignment of artefacts and the meanings ascribed to them. In this way, not only the understanding, but also the empirical world to understand is based on construction rather than perception.

CIS does not avoid criticism. Among the characterisations is the view that "the very notion of CIS is radically underspecified" (Randall 2000:17), and that

"there are a number of serious problems with the concept, and the way it is often used today. It would appear that rather than clarify matters, the label may only obfuscate" (Bannon 2000:1).
2.4 Shared understanding and integrated operations

In the traditional petroleum industry, the division of labour is accompanied by a division of knowledge. A high degree of specialisation poses a challenge to the actors when decisions need to be based on a holistic understanding, and when the goals guiding the decisions differ between different disciplines. As a consequence, decisions that are taken within one discipline may be suboptimal or even harmful from the viewpoint of another discipline. This may typically be the case when two disciplines adopt different time horizons for their work and its outcome. One example is the drilling department whose time horizon includes only the construction of a well, and the subsurface disciplines whose time horizon is considerably wider, including not only the well construction but the whole lifetime of the well. Another issue is that work in the petroleum industry has traditionally been performed in a mainly offline modus, with a considerate time delay between the creation of information and the use of this information for operative decisions.

These are among the challenges that are addressed by change processes that can currently be seen throughout the petroleum industry. The industry is undergoing a sociotechnical change process in the pursuit of more integrated operations. Technological and organisational efforts are made to modernise an industry which is characterised by disintegration both in terms of knowledge and geographical allocations (OLF 2005).

The strategy is given different names by different companies, such as e-field, intelligent field and smart field. In Norway, the term that has been commonly adopted is integrated operations. By tying people and information closer together across geographical distances and knowledge borders, the goal is to make offshore operations faster, better and safer (OLF 2005).

Closer integration of people, technology and information is one of the petroleum industry's responses to increasingly demanding operations with respect to reservoir characteristics, $\mathrm{HSE}^{3}$ and profitability. Integrated operations apply new technologies and new work processes to make data and information available to those who can make use of it, in real-time, to make collective and holistic decisions and to automate work processes. The technological innovations encompass a range of different aspects. New, more and better sensors shall provide more information of higher quality. Enhanced signal transportation along wired drill-pipes will make a radically increased sampling rate and bit rate of subsurface data available in real-time. Enhanced information processing renders realtime updating of better models possible. New systems for

\footnotetext{
${ }^{3}$ Health, safety and environment.
} 
monitoring operations will detect deviations that occur, or give warnings before they occur. Automation will, to some extent, substitute human reasoning and action and standardise operations so that they are performed consistently and within safe operations windows (Iversen et al. 2006, 2007; Rommetveit et al. 2004, 2008).

The new work processes involve closer integration of onshore and offshore personnel, as well as closer integration of different companies onshore. Better information and communication infrastructure will increase the use of video conferences and sharing of documents, pictures, graphs etc. The establishment of centralised expert centres will ensure that a limited number of experts can serve a large number of operations. A more global approach to operations and services will lead to the transcendence of time zones through a follow-the-sun allocation of tasks, presumptively resulting in faster, better and safer operations (Løwén et al. 2009; OLF 2005; Ringstad and Andersen 2006).

Shared understanding is a topic of much interest in relation to integrated operations (e.g. Andresen et al. 2006; Grøtan et al. 2009; Hepsø 2006; Rolland et al. 2006; Skarholt et al. 2008; Tinmannsvik 2008). A potential of technologies and work processes closely linked with integrated operations to promote shared understanding should be seen in relation to careful considerations of what shared understanding means in practice, and what role it plays in the cooperative work. This paper addresses these issues, and it does so by following the advice of Hollnagel (2009) and Dekker (2006) to study normal work rather than failures. Hollnagel claims that "(...) if the probability of failure is as high as $10^{-4}$, there are still 9,999 successes for every failure, hence a much better basis for learning" (Hollnagel 2009:83), therefore "we should try to understand and explain the normal, rather than the exceptions" (Hollnagel 2009:97).

\section{Method}

The study of shared understanding in cooperative work was undertaken as an observation study in an international petroleum company. Over a period of 8 weeks, the author joined an onshore rig team as an observant. The rig team is located in one of the company's five regional onshore offices responsible for following up the offshore operations on the Norwegian continental shelf. The team is responsible for all drilling operations at one specific field. During the fieldwork, one well project-the drilling of one wellwas observed from beginning to end.

The study offered an insight into the many different work processes within the team responsible for the offshore drilling operations. Access to the team was granted by the team leader (drilling superintendent), and allowed the author to join the team in their everyday work in their landscaped office and their daily video-conferences with the offshore rig crew and other partners. The author was also granted a nearly unrestricted admission to any ad hoc meetings that were held in the course of the operations.

During the observation study, which also involved participation in less formal settings such as coffee break discussions and the daily lunch break, the author became quite familiar with the members of the rig crew. As a supplement to the observation in professional work settings, this was a valuable trust-building socialisation that prepared the ground for the interviews that were conducted in the last part of the study, and for the gradual transition from pure observation to more participatory inquiries.

Four interviews were conducted, tape recorded and transcribed. The interviews were conducted in an informal, conversational manner that allowed the informants to focus on the topics that they themselves considered important in relation to cooperative work and shared understanding. Two of the interviewees were drilling engineers, a third was the team's HSE engineer and the fourth was a reservoir engineer. It should be noted that the reservoir engineer is not a member of the rig crew, but plays a central role in parts of the drilling operations. In addition to the four interviews related to the specific fieldwork from which the case (see Sect. 4) was collected, interviews from other fieldworks the author has undertaken in connection with the same research project have also been a useful resource for developing a richer understanding both of the case and of the role of shared understanding.

Apart from conducting observation and interviews, the author was also given access to the company's database where information about the organisation and its work processes, best practices and drilling programmes could be accessed. Considerable time was therefore also spent on literature review that helped contextualise the technical information and make it intelligible. With respect to making information from the professional petroleum domain intelligible to a social scientist, it should be mentioned that the author has a professional background as an offshore mudlogging geologist. This professional background was valuable in order to gain a relevant understanding of the rig team's work.

When not working individually in its landscaped office, the rig team works closely together with the offshore rig crew and offshore and onshore representatives from service companies that deliver equipment and services for the operations. It was thus not only the rig team that was studied, but a distributed, loosely coupled organisation that was constituted differently from meeting to meeting, depending on the meeting agendas. 
As often as possible, morning meetings were observed. A frequent attendance in these meetings offered the author a regular update of the drilling status. The same was the case for meetings where detailed operating procedures were reviewed before they were carried out. These meetings were held prior to special operations such as running of casing, cementing jobs, sidekicks etc. In addition, ad hoc meetings that were initiated by contingent events were especially interesting, since these meetings represented occasions where drilling problems were elaborated on the spot, with minimal preceding alignment of viewpoints between people and across disciplines.

In the regular morning meetings between the onshore rig team and the offshore rig crew, there was typically only a basic, minimum attendance. Offshore, this included the company man, the company drilling engineer, the toolpusher and the offshore installation manager. ${ }^{4}$ Depending on the operations, a geologist and a reservoir engineer were also present. Onshore, the standard staff consisted of the drilling superintendent, an HSE engineer, a logistics engineer, a drilling engineer and the leading drilling engineer. Additionally, operation-specific personnel including a geologist, a petrophysicist, a reservoir engineer and a drilling coordinator from a service company were also present. Furthermore, the onshore supply base was always present as a third party in the video conference. These different types of meetings are important arenas for the negotiation and sharing of information and knowledge, and they thus offered valuable empirical data to the study.

The study draws on different traditions within qualitative methods. As the research question and the themes in focus were not formulated clearly in advance of the observation study, but rather were highlighted by the observations and the interviews, the approach bears resemblance to Glaser and Strauss' (1967) grounded theory. Exactly what was looked for in the data material was highly influenced by the material itself. Garfinkel's (1967) ethnomethodology is another source of inspiration, directing the main focus on the informants' own descriptions and perceptions of their work rather than the scientist's interpretation of it.

As a central part of the method, informants have been involved as discussion partners in the rewriting process. Getting the details of the case right was crucial for elaborating the case in a relevant manner. It was also done in an attempt to stay as true as possible to the ethnomethodological approach.

\footnotetext{
4 The company man is the representative of the oil company, while toolpusher designates the supervisor for the drilling contractor.
}

\section{Perspectives and trade-offs: a case of depth measurement discrepancies}

Contingencies appear frequently in drilling operations. One challenge faced by the involved actors is thus to relate to new information that requires interpretation and negotiation and to revise plans and actions accordingly.

Cooperation between the different disciplines involved in the drilling operations involves extensive articulation work (Haavik 2010). The division of labour also implies a division of perspectives, goals and performance measures. Different disciplines will have different goals and consequently different performance evaluation criteria. The collective and complex task of drilling and production is characterised by one informant by the "inherent dilemmas of the petroleum industry". The decision-making involves trade-offs between efficiency and thoroughness (Hollnagel 2009), between conflicting goals among the disciplines and between short and long time perspectives. ${ }^{5}$ A common view is that drilling engineers have a short time horizon; their job is finished when the well is drilled. The success criteria are that they manage to drill the well technically optimally, with as few and gentle curves as possible, in safe distance from other wells in the area, with little down-time and no accidents. Reservoir engineers, on the other hand, have a longer time horizon for their work. The positioning of the well in the reservoir has a significant effect on the long-term drainage of the reservoir. Hence, whereas a decision regarding the well path in the reservoir is a question of technical possibilities for the drilling engineers, it is a question of long-term hydrocarbon flow, production and expected profit for the reservoir engineers. Consider the following statement from one informant:

"To the drilling engineers, a project may be successful if the well is drilled without collisions with other wells in the area and without experiencing any serious well control issues. To the reservoir engineers, on the other hand, a successful well is one that is located perfectly in the reservoir, as one well out of many, so that the total, long-term production from the reservoir will be as high as possible" (reservoir engineer).

Another informant addresses the issue by referring to specific strategic trade-offs between drilling efficiency and

\footnotetext{
5 Although other actors might be involved in issues like the one discussed in this paper, only two groups of actors will be considered in this discussion to make the argumentation clear and conceptual. The actors belong to the drilling and well department and the petroleum technology department and will in the following be labelled drilling engineers and reservoir engineers. The onshore rig team, which was the main locus of the fieldwork, consists mainly of drilling engineers.
} 
field knowledge development: a geologist might advise reducing the rate of penetration through a specific formation to sample the formation thoroughly. This could be a strategy to understand the larger field, and might not necessarily be of any value to the ongoing well project. In such a situation, the extra drilling time will be accounted for in the drilling budget, and the drilling engineers might therefore be reluctant to choose such a strategy since it represents an expense to their budget without any prospects to profits in the same budget.

Despite these conflicting interests, there is no way any of the disciplines can obtain their goals without collaborating closely with the other. The disciplines collaborate in every phase of a project, from planning to completion. They are also aware that one discipline's goal achievement is worthless if it means that the other discipline does not reach its goal. The different goals and perspectives are typically made current when the agreed drilling programme is challenged by contingencies. The case description below is a case of such contingencies, and it illustrates the main point of this article. The different ways of relating to and accounting for the discrepancies reflect more that simply different goals; they reflect different epistemological approaches that do not easily integrate to support the different aspects of shared understanding. The case does not appear as an extraordinary event for the involved actors, and the handling of the situation is described as ordinary work. $^{6}$

\subsection{Case description: depth measurement discrepancies}

The rig team that was studied is located in one of the operating company's five onshore operative offices along the west coast of Norway. The office operates six offshore fields, each field represented by one rig team. The responsibilities of the teams are to produce drilling programmes and to follow up their execution.

A well is drilled in several sections. Each section has a different diameter, largest for the upper section and the smallest in the last section, which penetrates the reservoir. A typical sequence of sections' diameters is 36" (inches), 26", 171/2", 12/ " " and $8 \frac{1}{2}$ ". The transition between sections is often determined by the boundaries between two geological layers. These boundaries therefore play a role both in the drilling process and in the later production stage since the boundaries define areas from which oil can be produced. Other types of boundaries that are used for navigation are the interfaces between fluid and gas phases

\footnotetext{
6 To the extent that any work in drilling operations can be described as ordinary; the contingent, non-standardised nature of drilling operations, where the underground formations never are identical in two operations, and never are fully known, implies that every ordinary work process still is unique.
}

such as the gas/oil contact and the oil/water contact in the reservoir. It was uncertainty in connection with the depth measurement of such boundaries during a drilling operation that formed the point of departure for the case. ${ }^{7}$ The schematic presentation of the case offered in Fig. 1 below might be a useful reference for the following case description.

The drilling programme advised placing the $81 / 2$ " well section horizontally in the reservoir in a position relative to the gas/oil contact and the oil/water contact that would secure production of oil without influx of gas or water. To do that, it was crucial to determine the precise depth of either the gas/oil contact or the oil/water contact. These depths were found by logging the pressure gradient and the resistivity of the fluid across a depth section. A break in the pressure gradient will indicate the contact zone between different fluids. An accurate determination of the depth of top Garn formation (oil reservoir) was also important since it defined the top of the reservoir.

In connection with depth measurements, it should be noted that there are two different types of depth values; measured depth and vertical depth. Measured depths are calculated as the sum of every joint making up the drill string from surface to the drill bit. The composition of the drill string is listed in a manually produced paper or computer file, the tally. Vertical depths are then calculated on the basis of the measured depth and the curvature of the well path.

In the case, the reservoir was first drilled into with a $12 \frac{1}{4}$ " drill bit. The Garn formation was identified and the vertical depth of the formation top was measured/calculated. Top Garn was identified 141/2 $\mathrm{m}$ deeper than forecasted. The gas/oil contact was not found. This could, according to the informants, be due to a non-horizontal boundary between top Garn and the overburden formation, and a penetration of Garn at location $x$ and not at, for example, location y as shown in Fig. $1 .{ }^{8}$ It was therefore decided to continue drilling a pilot well (see Fig. 1) through the oil/water contact with an $8 \frac{1}{2}$ " drill bit, and then use the oil/water contact as a depth reference point instead of the gas/oil contact. Before this could be done, a casing needed to be run to secure the $12 \frac{1}{4}$ " hole. At known

\footnotetext{
7 Several situations that appeared during the field study could have served to illustrate the point of the article. The actual case was chosen partly because it served well to illustrate the different aspects of shared understanding, partly for practical reasons; it elapsed during a limited period of time and involved actors whose contributions were possible to get an overview of during the observation and the following interviews.

${ }^{8}$ There was no gas/oil contact present at that location. Due to different specific gravities, the fluids in the reservoir will migrate so that gas gets on top, oil in the middle and water on bottom. The border between Garn and the overburden formations is impermeable. Figure 1 shows the position of the well and of the gas/oil contact.
} 
Fig. 1 Placing the well in the reservoir (the figure is conceptual and not correct in scale or details)

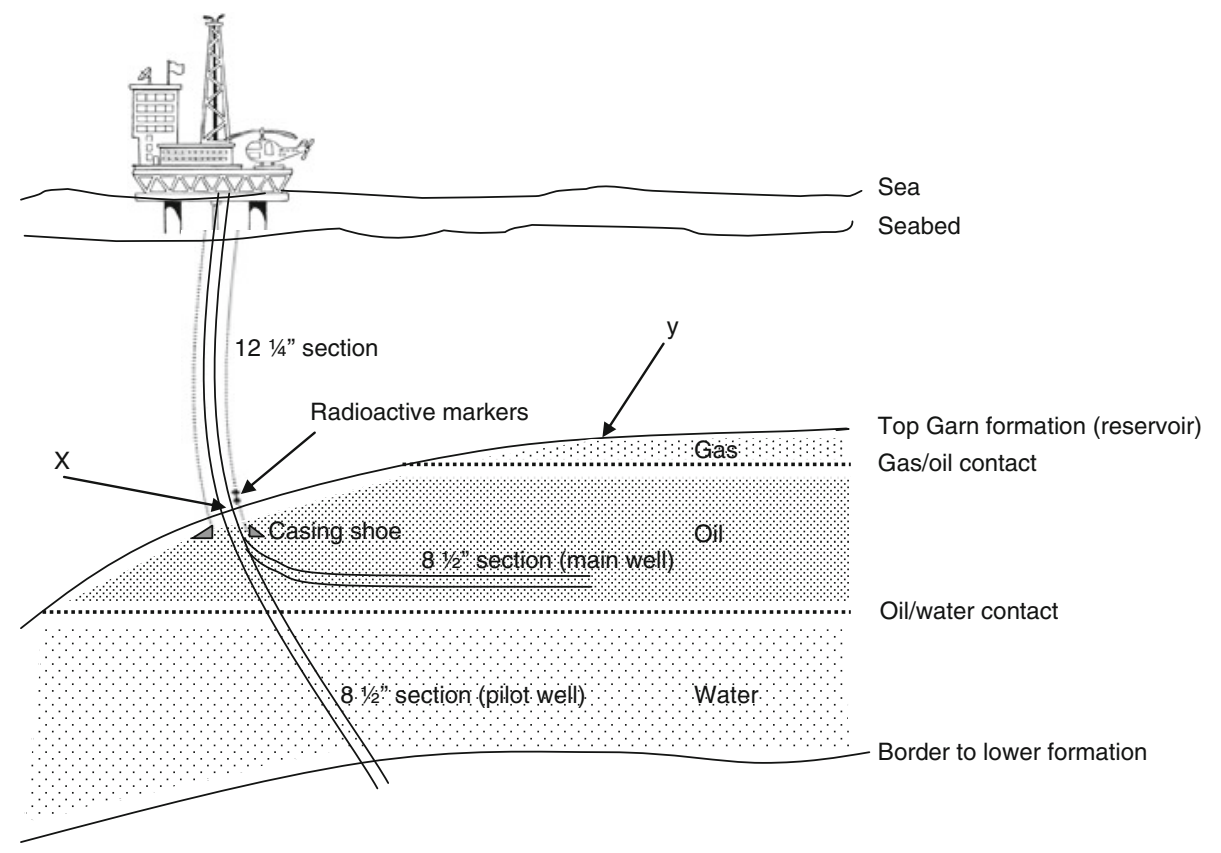

positions inside this casing, a few radioactive markers were placed to function as easily detectable depth reference points for the next drilling section.

When the drill string subsequently was run into the hole and through the casing with an $8 \frac{1}{2}$ " drill bit some unexpected depth discrepancies were observed: Top Garn was identified $4.5 \mathrm{~m}$ deeper in the $81 / 2$ section than in the $12 \frac{1}{4}$ section. In addition, when the depth of the radioactive markers was logged, there was a discrepancy of 1.9 and $0.5 \mathrm{~m}$, respectively between the two measurements. Although it was the oil/water contact and not the Top Garn or the radioactive markers that was the reference points to be used when later kicking off laterally for the main well (see Fig. 1), this discrepancy raised a dilemma: which measurements were correct-those measured in the $12 \frac{1}{4}$ " section or those of the $81 / 2$ "? And if the $81 / 2$ " pilot well measurements were unreliable, how could they serve as a reference for the subsequent main bore? As we shall see, this last question was related to differently by different disciplines in the organisation.

Apart from this main depth issue, there was another topic that indirectly related to the main issue and that had some of the same characteristics with respect to how it was related to by the different disciplines. In a video conference between the onshore rig team and the offshore rig crew, the offshore operational geologist argued that they should take more pressure measurements in the reservoir than initially planned for. The rationale for this was to get a better understanding of the structure and the geology of the reservoir and to be able to make more accurate model descriptions of the boundaries between the gas, oil and water for the larger field. The drilling engineers would rather avoid this, since such operations are time consuming and increase the risk of getting stuck due to the standstill of the pipe during such measurements.

There were thus two issues that the drilling organisation had to relate to, and did differently. First, there was the question of the different depth measurements and the uncertainty of their reliability. This will be called issue A; the second issue regarded the number of pressure measurements to be taken, and this will be called issue B.

\subsection{Possible explanations elaborated by the participants}

Issue A was the most troublesome, since there were so many uncertainties attached to it. There were many possible sources of error, challenging the reliability of any accounts of the state of affairs. The issue was first treated in the morning meeting, which was conducted as a video conference between the rig and the onshore team. After the meeting, the reservoir engineers (offshore and onshore) and the drilling engineers (onshore) discussed the issue separately. The issue was again brought up at the morning meeting the following day. The alternative explanations that were discussed in this meeting will be briefly reviewed below.

During the meeting, six main potential sources of error causing the measurement discrepancy were identified. The first potential source was an error in the tally, where the lengths of all components of the drill string are listed. If the tally did not correspond to the actual make-up of the drill string, the measured depth would be erroneous. The second potential source were the radioactive markers which might have loosened and been pushed upwards 
when running the casing downwards, thus contributing to the error. The third potential source was the tide which according to the informants was not usually taken into account during operations of this kind. ${ }^{9}$ If the depth measurements were not correlated to the corresponding level of the tide for the two measurements, the variance could amount to $1 \frac{1}{2}$ to $2 \mathrm{~m}$. The fourth potential source was a possible difference in the stretching of the drill string due to the string's weight in the respective sections. In the $12 \frac{1}{4} "$ section, during the casing running, the stretching of the drill string would be negligible. In the $8 \frac{1}{2}$ " section, on the other hand, the drill string was run into an open hole and would be much more stretched. This would theoretically lead to a too small depth measurement. An informant made it clear after the meeting that they usually not did account for such variations. The fifth source was the identification of the top Garn formation in the two runs, which was based on resistivity measurements in the formation and was subject to human interpretation of resistivity logs. The sixth source was the amount and the effect of ballast on the rig during the two runs. It was concluded that ballast could lower the rig by as much as $2-3 \mathrm{~m}$ in the sea. The participants were not sure whether any differences in ballast had been accounted for in the two measurements.

Issue $\mathrm{B}$ was not subject to as much discussion. In the second morning meeting, the offshore geologist requested taking more pressure points than initially agreed upon in the reservoir section. No decision was made at the time, but the geologist was asked to reconsider whether this was really necessary. The issue was elaborated on by some of the rig team members during lunch the same day. One drilling engineer commented that every extra pressure point takes half an hour and costs approximately US \$8000. Another engineer made the remark that the price of such measurements might not be the worst factor. The increased chance of getting stuck due to standstill of the pipe when the pressure points are being taken would be more serious. He concluded that "we don't want to spend time on things we don't need". A third engineer added, humorously: "Things we don't need, no...", addressing with obvious self-irony the different requirements of the different disciplines and the difficulties of meeting them all concurrently.

The depth discrepancy issue was never fully solved. The possible explanations were discussed and attempts were made to combine them to see if they could sum up to the difference between the measurements. However, when the drilling operation continued into the $81 / 2$ " section, there existed only different theories and no unambiguous solution to the case. It was agreed to proceed without any

\footnotetext{
9 The installation was a floating rig, and hence the level of the tide has significance for the depth measurements.
}

absolute references of depth, and to place the well relative to the oil/water contact and to be attentive to any clues that might appear on the way.

\subsection{The meaning of uncertainty to different disciplines}

The drilling engineers represent the organisational owners of depth measurements and positioning of the well. A reservoir engineer explained that

"These measurements are vitally important to the drilling engineers to determine the exact well path only after a well is constructed. Controlling this means that future wells can be planned for with sufficient margins in order to avoid collisions with older wells. To the reservoir engineers, on the other hand, the significance of real-time positions is vital. The accuracy and reliability of measurements are decisive, and they are so during drilling."

The informant continues to explain that the view among the reservoir engineers is that the drilling engineers have much lower requirements for accuracy in the drilling operations than the reservoir engineers, and that the drilling contractors are known to be approximate about depth measurements. It is also a general view among drilling engineers that reservoir engineers often demand accuracies that are meaningless given the reliabilities of the methods of measurement. The informant used the case as an example; the reservoir engineers want to investigate the reason for the measurement deviances in order to reduce the deviances to decimetres, while the accuracy of the measurements exceeds those limits by far. A drilling engineer emphasises that "some degree of data uncertainty is impossible to avoid. We just have to live with that". The main difference in the way drilling engineers and reservoir engineers relate to the uncertainties could perhaps be illustrated by the following quote from a reservoir engineer: "When you talk to drilling people, there are very few who want to hear about uncertainties. Drilling people only wants a yes or no". Understanding the different significance of uncertainties to different disciplines is important for understanding what the measurement discrepancies in the case mean to the different actors.

\section{Discussion}

In the introduction it was claimed that poor performance and accidents are often held to be caused by a lack of shared understanding, without accounting for the role shared understanding actually plays in normal, collaborative work. By simply showing the correlation between accidents and breakdown in shared understanding, and not 
accounting for the causal connections between shared understanding and successful work, accident investigators run the risk of drawing incomplete or even wrong conclusions with respect to what caused the accident. In the above case, none of the three conceptualisations of shared understanding are identified as suitable models for the driving forces of successful collaboration. To the contrary, shared understanding does not enter into the description of the work. This is surprising if lack of shared understanding is believed to unambiguously affect the collaborative work and its result in a negative way.

Based on the case reviewed in Sect. 4, the subsequent sections elaborate in which way shared understanding is relevant to the work of the drilling engineers and the reservoir engineers. In order to understand the effect of shared understanding, such an analysis should be undertaken in accordance with specific and unambiguous definitions. In addition, the limits of the concepts' explanatory power must be acknowledged. Since each concept covers a nonexhaustive part of shared understanding, a central point must be to identify what is outside of each concept's scope, and what the implications are when different concepts are incompatible within the same area of application.

\subsection{Handling the uncertainties}

In the course of the case, the participants elaborated on their different requirements with respect to issue A. The reservoir engineers argued for an investigation of the measurements discrepancy in order to establish an undisputed understanding of the true state of the well. Such a realist decision-making strategy might well end up with a shared situation awareness. Although the epistemological preconditions for situation awareness are not clearly defined, the statement that "it is entirely possible to have perfect SA, yet make an incorrect decision" (Endsley 2000:8) points towards a realist epistemology. It is hard to think of a perfect situation awareness and a wrong decision without relying on the correspondence theory of truth (Latour 1999). However, correspondence is not an unambiguous requirement in drilling operations. The goals of a discipline influence the state of affairs. The reservoir engineers' wish to calculate exactly the stretch effect of the drill string on the measured depth illustrates this; from the drilling engineers' point of view this was not relevant since this stretch of the drill string under any circumstance would be much smaller than the overall depth uncertainty. What was considered as shared situation awareness by the reservoir engineers was considered as an illusion by the drilling engineers.

The strategy suggested by the drilling engineers was to abandon the ambition of acquiring any absolute points of reference and just keep future measurements relative to the last measurement, undertaking the forthcoming measurement in the exact same way with identical equipment as in the last measurement. In that way many uncertainties would become irrelevant; if they had missed out an element of the drill string, they would 'miss it out' again by applying the same drill string configuration. If the radioactive markers were out of position, they would still be at the same position in the next run, since the casing would not have moved in the meantime. The identification of top Garn formation would follow the same interpretation principles. Hence, by using the measurements of the last section as a reference point for the next, it would be of less interest whether these measurements were correct or not, given that the tide and the ballasting during that last run was accounted for. This approach would involve an expansion of a CIS into the near future, leaving the configuration of tools and the interpretation of information unaltered from one situation to the next. This strategy suggests a more relativistic form of understanding than the first approach. Whereas the first approach is based on a form of understanding based on 'objective facts', the second approach is based on a pragmatic and a constructivist understanding, on the construction of a CIS.

The choice of approach has consequences beyond the actual well project. The first approach will contribute to an understanding not only of the actual reservoir but also to the wider geomodel of the whole field. The second approach might serve the accuracy of the singular well better than the first approach, and is not based on the accuracy of measurements as much as on the reliability of relationships between measurements. The drawback is that the value potential will not be transferred to the wider geomodel, as in the first approach, since the location-specific context of the uncertainty cannot be transferred to operations situated elsewhere.

Issue A (the depth discrepancy) was not discussed in isolation from other issues. One such issue was issue B (the number of pressure points), since "the pressure gradient could be used to determine the oil/water contact and thus make oil/water contact an external depth reference that can be reused in later operations" (reservoir engineer). In addition, "the gradient could give important information about the reservoir with respect to faults and prospects for future production" (same informant). Issue B could thus be understood as an integrated part of issue A in light of a realist strategy, and it could contribute to the preferred approach of the reservoir engineers. On the other hand, as already noted, the drilling engineers were not enthusiastic about pursuing issue B since it would involve extra costs that would not contribute to their understanding of the state of affairs.

With the different perspectives on how to handle the measurement discrepancies with respect to the local/global 
and the short and long time perspective, perhaps common ground could be the missing link needed to negotiate the optimal solution? As we shall see in the following sections, neither common ground, shared situation awareness nor CIS, as concepts for shared understanding, are fully adequate to support the work and the decisions needed to handle the discrepancies in the case.

\subsection{Not just an issue of communication (common ground)}

Achieving common ground, or "mutual knowledge, mutual beliefs, and mutual assumptions" (Clark and Brennan 1991:127) with respect to the ongoing operations does not seem to be the primary challenge for the cooperative work. The drilling engineers and the reservoir engineers are well aware of each other's perspectives and needs with respect to data accuracy. The elaboration by a drilling engineer on the limitations with regard to reliability of the measurements wanted by the reservoir engineers shows that the coordination of decisions related to the case depends more on trade-offs between accuracy and reliability than on obtaining common ground. Mutual knowledge, beliefs and assumptions do not concern the specific situation as much as they concern the larger goal, which is presented in the drilling programme of the actual well as "to drain as much oil [...] as possible from the [...] reservoir". Whether the decision is based on the first approach of investigating the difference in measurements to establish an undisputed understanding of the true state of the well or the second approach of abandoning the search for absolute points of reference and rather keep future measurements relative to measurements performed with identical equipment, hinges more on a clear formulation of an overarching goal of the operations than on mutual knowledge, beliefs and assumptions - common ground-with respect to the case of the depth measurements discrepancies. It is on the overarching level that the decisions can rely on a social construction. In such specific situations as the present case, the depth references must also be based on physical measurements of depth and on a specific configuration of the drill string.

\subsection{Objectivity is relative (shared situation awareness)}

The perception of issue $\mathrm{A}$ and issue $\mathrm{B}$, and their interdependence, depends on whether it is based on a short or a long time perspective. According to Endsley and Jones (1997:20), "situation awareness is highly impacted by a crew member's goal and expectations". However, since there are at least two different solutions to the case problem, one unique reference against which to evaluate its correctness does not exist. The solution cannot simply be perceived, it has to be constructed; the participants must choose how the depth measurements should be handled. The first, objectivistic approach, which could be justified with reference to situation awareness, is the one favoured by the reservoir engineers. The advantage with this approach is that it is relevant for the larger field and hence can add to the long-term value-creation. The paradox is that due to the mentioned limited accuracy of measurement (see Sect. 4.3) such an approach can turn out to be nonoptimal in the short time perspective, when only the actual well is accounted for. Thus, a non-contextual evaluation of this specific well project and the team that undertook it could be unfavourable. Furthermore, since the actual drilling process is managed by the drilling engineers, not by the reservoir engineers, it is difficult to argue for such an approach. As stated by a drilling engineer: "Some degree of data uncertainty is impossible to avoid. We just have to live with that".

\subsection{Relativity has a limited reach (CIS)}

More than a collective mental state corresponding to an objective reality, the challenge of the rig team is to negotiate and to construct the well with the information and tools that are available. Seeing the activity to recover control over the drilling operations as an effort to construct a CIS renders a variety of extra resources such as the drill string configuration and relative measurements available to the participants. With such a perspective, relativity and context is introduced as an ingredient of knowledge. Besides, the epistemology that makes such a perspective possible allows for construction to supplement the less powerful process of perception. This sociotechnical construction is more comprehensive than the social construction discussed previously, but not necessarily fully adequate. Instead of viewing the measurement discrepancies as a problem of communication (common ground) or shared perception (shared situation awareness), this approach would find the challenge to be an issue of actively combining the available social and technical resources (CIS) into a stable configuration. By including the context of the measurements of different sections of the well in the measurements, the measurements turn relative. In this case, the context is made up of the identified six potential sources of error highlighted in Sect. 4.2. Including the context means that the measurements of depths in one section is transformed from an isolated, objective measurement into a relative measurement that includes a drill string configuration both of the current section and the sections to come. The implications of such an approach is, however, not unproblematic, as shown by this case; whereas it may increase the reliability of the depth measurements of the different sections in the current well, it 
may reduce the reliability of the same measurements in future operations where the stability of the CIS has not been maintained because the context is impossible to reproduce.

Here, the tension between local and global is made current. This tension has been emphasised by others (e.g. Rolland et al. 2006). The dialectic character of a CIS suggests that it is a temporal entity whose unambiguous configuration is problematic to transport to another location in a future operation. In this case, an extension of the CIS would depend on reproducing the potential sources of uncertainty at another location. However, since every location and every operation need equipment and drilling strategies that are adapted to the local conditions, such an extension of the CIS would be based on an illusion.

\section{From shared understanding to distributed cognition. Conclusions}

A case of measurement discrepancies has been reviewed in light of different concepts of shared understanding. The review has been undertaken to investigate how shared understanding can play an active part in negotiating a solution to the problem. What the case shows, however, is that shared understanding is not a requisite in this work. The different concepts of shared understanding investigated may contribute to solutions that are valid for a specific time/space combination, ${ }^{10}$ but when it comes to supporting solutions that are valid across a wider time/ space domain, ${ }^{11}$ they are shown to be less functional, even contradictory. The limited functionality can be traced back to each concept's limited area of application (cf. Sect. 5.25.4). The contradictory aspect has to do with the incompatible epistemologies that the different concepts of shared understanding are based on (cf. Sects. 2.1-2.3 and 5.2-5.4). These limitations could be compared to the limitations of a map projection where a three-dimensional geographic relationship is transformed to a two-dimensional surface; a map projection may be conform (areas are correctly represented) or equivalent (areas are correctly represented) or equidistant (distances are correctly represented), but it cannot satisfy the demands of more than on projection at a time.

Shared understanding is a central phenomenon in collaborative work, and this case study does not challenge its position as a descriptive phenomenon as such. What it challenges is the position of shared understanding as a causal agent in collaborative work where the goals of the different actors are not unanimous. In such work, where

\footnotetext{
$\overline{10}$ The specific well.

${ }^{11}$ Future wells and the larger geomodel.
}

there is a need for negotiations and mutual adaptation of the empirical world to the different goals and available methodologies, the shortcomings of shared understanding must be acknowledged. Rather than shared, the relevant collective understanding could be described as distributed, and although this distributed understanding in itself may have limited causal powers, it is closely connected to the more powerful concept of distributed cognition whose significance is well documented by other authors (e.g. Artman and Garbis 1998; Hutchins 1995a, b) and which this case also may serve as an illustration of.

\section{Epilogue}

The well construction process was brought to an end with a satisfactory result in spite of the uncertainties with respect to the depth measurements. The final well report that more than a year later sums up the operation, the results and the experiences eventually offers a shared understanding of what was going on. However, the significance of this shared understanding is characterised by its post-hoc character and the fact that the report does mention the case at all.

Acknowledgments This research has been funded by the Norwegian Research Council's Petromaks programme.

Open Access This article is distributed under the terms of the Creative Commons Attribution Noncommercial License which permits any noncommercial use, distribution, and reproduction in any medium, provided the original author(s) and source are credited.

\section{References}

Aeronautica Civil de Colombia (1996) Aircraft accident report: controlled flight into terrain, American Airlines flight 965, Boeing 757-223, N651AA near Cali, Colombia, 20 Dec 1995. Aeronautica Civil, Bogota, Colombia

Almklov PG (2006) Kunnskap, kommunikasjon og ekspertise et antropologisk studium av en tverrfaglig ekspertgruppe i oljeindustrien. Norges Teknisk-Naturvitenskapelige Universitet, Fakultet for Samfunnsvitenskap og Teknologiledelse, Trondheim

Andresen G, Grøtan TO, Johnsen SO, Rossness R, Sivertsen T, Steiro T, Thunem A, Tveiten C (2006) Samhandling over avstanderfaringer av relevans for petroleumsbransjen. SINTEF, Trondheim

Antonsen S (2009) Safety culture: theory, method and improvement. Ashgate Pub Co, Denmark

Artman H, Garbis C (1998) Situation awareness as distributed cognition. In: Cognition and cooperation: Proceedings of 9th conference of cognitive ergonomics, Limerick, pp 151-156

Bannon L (2000) Understanding common information spaces in CSCW. Paper presented at the workshop on cooperative organisation of common information spaces. Technical University of Denmark, Denmark 
Bannon L, Bødker S (1997) Constructing common information spaces. In: Proceedings of the fifth conference on European conference on computer supported cooperative work. Kluwer Academic Publishers, Lancaster, pp 81-96

Beers PJ, Boshuizen HPA, Kirschner PA, Gijselaers WH (2005) Computer support for knowledge construction in collaborative learning environments. Comput Human Behav 21(4):623-643

Billings CE (1996) Situation awareness measurement and analysis: a commentary. In: Garland DJ, Endsley MR (eds) Experimental analysis and measurement of situation awareness. Embry-Riddle Aeronautical University Press, Daytona Beach, pp 1-6

Bossen C (2002) The parameters of common information spaces: the heterogeneity of cooperative work at a hospital ward. In: Proceedings of the 2002 ACM conference on Computer supported cooperative work. ACM, New Orleans, pp 176-185

Brown JS (1991) Organizational learning and communities-ofpractice: Toward a unified view of working, learning, and innovation. Organ Sci 2(1):40-57

Clark HH, Brennan SE (1991) Grounding in communication. In: Resnick LB, Levine JM, Teasley SD (eds) Perspectives on socially shared cognition. American Psychological Association, Washington, pp 127-149

Dekker S (2006) Resilience engineering: chronicling the emergence of confused concensus. In: Hollnagel E, Woods DD, Leveson N (eds) Resilience engineering, concepts and precepts. Ashgate, Aldershot, pp 77-92

Dekker S, Hollnagel E (2004) Human factors and folk models. Cogn Techno Work 6(2):79-86

Endsley MR (1988) Design and evaluation for situation awareness enhancement. In: Proceedings of the human factors society 32nd annual meeting. Human Factors and Ergonomics Society, Santa Monica, pp 97-101

Endsley MR (1999) Shared situation awareness in the flight deckATC system. IEEE Aerosp Electron Syst Mag 14(8):25-30

Endsley MR (2000) Theoretical underpinnings of situation awareness: a critical review. In: Endsley MR, Garland DJ (eds) Situation awareness: analysis and measurement. Lawrence Erlbaum Associates, Mahwah, pp 3-28

Endsley MR, Jones WM (1997) Situation awareness, information dominance, and information warfare (no. Al/cf-tr-1997-0156). Technical Report 97-01, United States Air Force Armstrong Laboratory, Texas

Engeström Y, Middleton D (1996) Cognition and communication at work. Cambridge University Press, Cambridge

Fields B (2005) Representing collaborative work: the airport as common information space. Cogn Techno Work 7(2):119-133

Flach JM (1995) Situation awareness: proceed with caution. Hum Factors 37(1):149-157

Garfinkel H (1967) Studies in ethnomethodology. Prentice-Hall, Englewood Cliffs

Glaser BG, Strauss AL (1967) The discovery of grounded theory: strategies for qualitative research. Aldine, Chicago

Grice HP (1975) Logic and conversation. In: Cole P, Morgan JL (eds) Syntax and semantics. 3, speech acts. Seminar Press, New York, pp 225-242

Grøtan TO, Albrechtsen E, Skarholt K (2009) How shared situational awareness influence organizational accident risk in the offshore oil industry. In: 18th European safety and reliability conference (Esrel 2009). CRC Press, Prague, Czech Republic, pp 2207-2214

Haavik T (2010) Making drilling operations visible: the role of articulation work for organisational safety. Cogn Techno Work 12(4):285-295. doi:10.1007/s10111-010-0139-2

Heath C, Knoblauch H, Luff P (2000) Technology and social interaction: the emergence of 'workplace studies'. Br J Sociol 51(2):299-320
Heath C, Luff P (1992) Collaboration and control: crisis management and multimedia technology in London underground line control rooms. Comput Support Coop Work 1(1):24-48

Heps $\varnothing$ V (2006) When are we going to address organizational robustness and collaboration as something else than a residual factor? Paper presented at the SPE 100712, 2006

Hollnagel E (2009) The ETTO principle: efficiency-thoroughness trade-off-why things that go right sometimes go wrong. Ashgate, Aldershot

Hutchins E (1995a) Cognition in the wild. MIT Press, Cambridge

Hutchins E (1995b) How a cockpit remembers its speeds. Cogn Sci 19(3):265-288

Iversen F, Cayeux E, Dvergsnes EW, Gravdal JE, Vefring EH, Mykletun B, Torsvoll A, Omdal S, Merlo A (2006) Monitoring and control of drilling utilizing continuously updated process models. Paper presented at the IADC/SPE Drilling Conference. Miami, Florida

Iversen F, Cayeux E, Dvergsnes EW, Welmer M, Torsvoll A, Merlo A (2007) Demonstrating a new system for integrated drilling control. Paper presented at the AADE National Technical Conference and Exhibition. Houston, Texas

Janis I (1972) Victims of groupthink. Houghton Mifflin Boston

Kaarstad M, Rindahl G, Torgersen G, Drøivoldsmo A (2009) Interaction and interaction skills in an integrated operations setting. Paper presented at the IEA 2009, 17th world congress on ergonomics. Beijing, China

Klein G (2005) Common ground and coordination in joint activity. In: Rouse WB, Boff KR (eds) Organizational simulation. WileyInterscience, Hoboken, pp 139-157

Koschmann T, LeBaron CD (2003) Reconsidering common ground: examining Clark's contribution theory in the OR. Paper presented at the European computer-supported cooperative work (ECSCW 03). Helsinki, Finland

Latour B (1987) Science in action: how to follow scientists and engineers through society. Open University Press, Milton Keynes

Latour B (1999) Pandora's hope: essays on the reality of science studies. Harvard University Press, Cambridge

Løwén S, Nygård BE, Østensen S, Lund T (2009) Subsurface support centre: a hub for communication of knowledge. Paper presented at the SPE digital energy conference and exhibition. Houston, Texas

MacMillan J, Entin EE, Serfaty D (2004) Communication overhead: the hidden cost of team cognition. In: Salas E, Fiore SM (eds) Team cognition: understanding the factors that drive process and performance. American Psychological Association, Washington, pp 61-82

Munkvold G, Ellingsen G (2007) Common information spaces along the illness trajectories of chronic patients. In: Proceedings of the 10th European conference on computer supported cooperative work, Limerick, Ireland, pp 291-310

National Transportation Safety Board (1994) Safety study: a review of flightcrew-involved major accidents of US air carriers, 1978 through 1990. NTSB, Washington

Nofi AA (2000) Defining and measuring shared situational awareness. Center for Naval Analyses, Alexandria, Virginia

OLF (2005) Integrated work processes: future work processes on the Norwegian continental shelf. Oljeindustriens Landsforening, Stavanger

Randall D (2000) What's common about common information spaces. Paper presented at the workshop on cooperative organisation of common information spaces. Technical University of Denmark

Ringstad AJ, Andersen K (2006) Integrated operations and HSEmajor issues and strategies. Paper presented at the SPE 
international conference on health, safety, and environment in oil and gas exploration and production. Abu Dhabi, UAE

Rolland KH, Heps $\varnothing$ V, Monteiro E (2006) Conceptualizing common information spaces across heterogeneous contexts: mutable mobiles and side-effects of integration. Paper presented at the proceedings of the 2006 20th anniversary conference on computer supported cooperative work. Banff, Alberta, Canada

Rommetveit R, Bjørkevoll KS, Halsey GW, Larsen HF, Merlo A, Nossaman LN, Sweep MN, Silseth KM, Ødegård SI (2004) Drilltronics: an integrated system for real-time optimization of the drilling process Paper presented at the IADC/SPE Drilling Conference Dallas, Texas

Rommetveit R, Bjørkevoll KS, Ødegård SI, Herbert M, Halsey GW, Kluge R (2008) Edrilling used on ekofisk for real-time drilling supervision, simulation, 3D visualization and diagnosis. Paper presented at the SPE intelligent energy conference and exhibition. Amsterdam, The Netherlands

Roth EM, Multer J, Raslear T (2006) Shared situation awareness as a contributor to high reliability performance in railroad operations. Organ Stud 27(7):967-987

Schmidt K, Bannon L (1992) Taking CSCW seriously: supporting articulation work. Comput Support Coop work 1(1):7-40

Schulman PR (1993) The negotiated order of organizational reliability. Adm Soc 25(3):353-372

Skarholt K, Næsje P, Heps $\varnothing$ V, Bye AS (2008) Integrated operations and leadership-how virtual cooperation influences leadership practice. In: Martorell S, Guedes Soares C, Barnett J (eds), Safety, reliability and risk analysis: theory, methods and applications. Proceedings of the European safety and reliability conference, esrel 2008, and 17th SRA-Europe. Taylor \& Francis Group, London, pp 821-828

Stanton N, Stewart R, Harris D, Houghton R, Baber C, McMaster R, Salmon P, Hoyle G, Walker G, Young M (2006) Distributed situation awareness in dynamic systems: theoretical development and application of an ergonomics methodology. Ergonomics 49(12):1288-1311

Suchman L (1996) Constituting shared workspaces. In: Engeström Y, Middleton D (eds) Cognition and communication at work. Cambridge University Press, Cambridge, pp 35-60

Tinmannsvik RK (2008) Robust arbeidspraksis: Hvorfor skjer det ikke flere ulykker på sokkelen? Tapir akademisk forl., Trondheim

Tjora AH (2000) The technological mediation of the nursing-medical boundary. Sociol Health Illn 22(6):721-741

TRADOC (1995). Tradoc pamphlet 525-69. Military operations: concept for information operations. Retrieved 8 Sept 2010, from http://www.iwar.org.uk/iwar/resources/tradoc/p525-69.htm

Weick KE (2007) The generative properties of richness. Acad Manage J 50(1):14

Weick KE, Roberts KH (1993) Collective mind in organizations: heedful interrelating on flight decks. Adm Sci Q 38(3):357-381 